\title{
Sunshine ER Tracker
}

\section{A homegrown electronic resources management system (ERMS)--University of Florida}

\section{Sunshine in a nutshell}

- Tracks orders and payments for UF Libraries electronic resources

- Covers FY 2015- present

- Built with Microsoft Access

- Full implementation June 2016

Why did we build Sunshine?

- To prepare reports for budget and collection managers

- Review price increases for renewals

- Allocate annual expected expenditures

- Error-checking (double-entry)

Why not use an existing ERMS?

- Cost

- Complexity

- Lack of customizability

- Difficult to match ILS data with ERMS knowledgebase

- Difficult to populate with cost data

\section{Why Microsoft Access?}

- It was there! (already licensed)

- Highly customizable

- Can populate the database with data from ILS, subscription agents, and other sources (XML, Excel, \& CSV)

- Use calculated fields: .eg. cost change

- Can produce reports \& summaries that can be sorted \& filtered, and exported to Excel

- Can run batch updates

- Backend-client structure allows multiple staff to access from anywhere on network \& use clients customized for staff roles
Electronic Resources Unit client

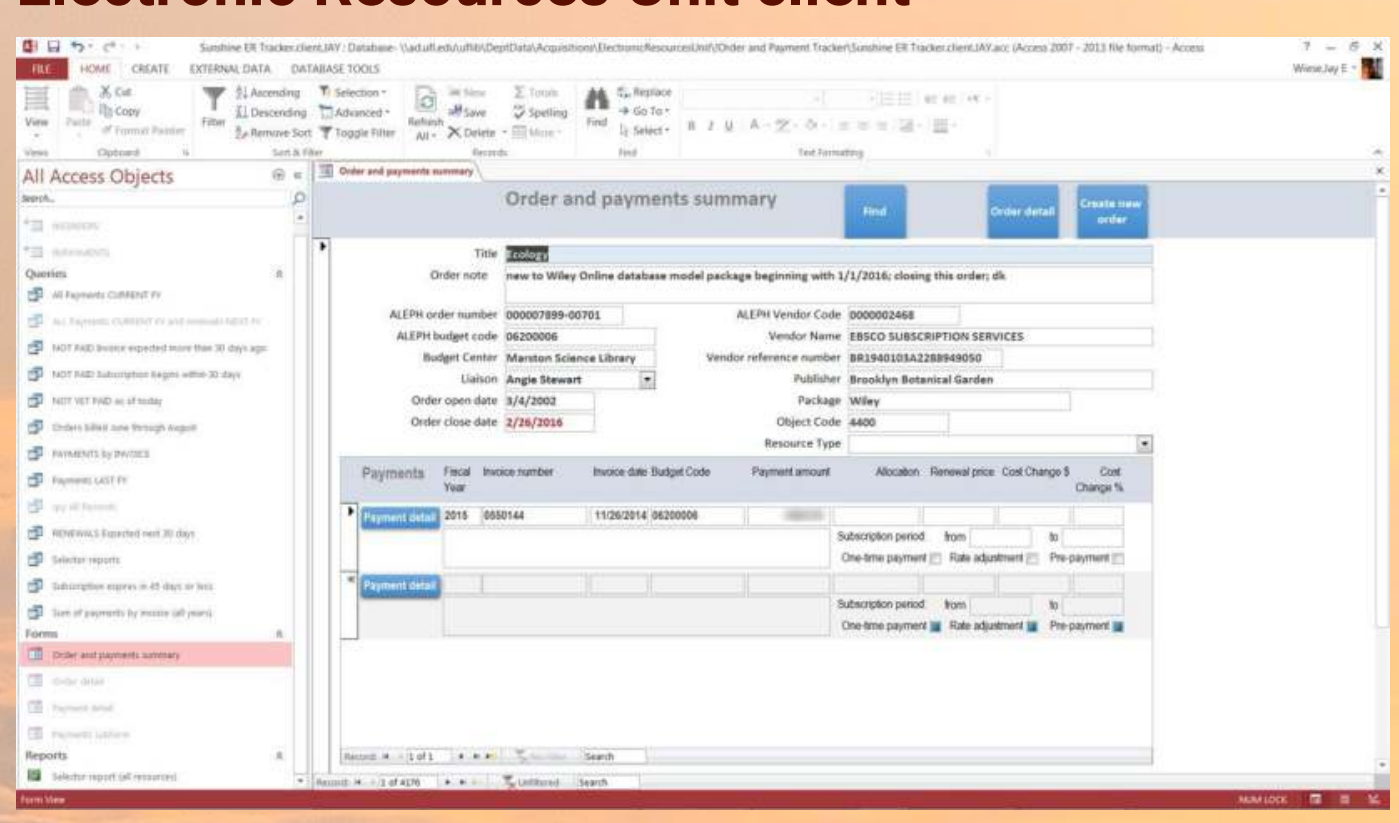

Budget manager client

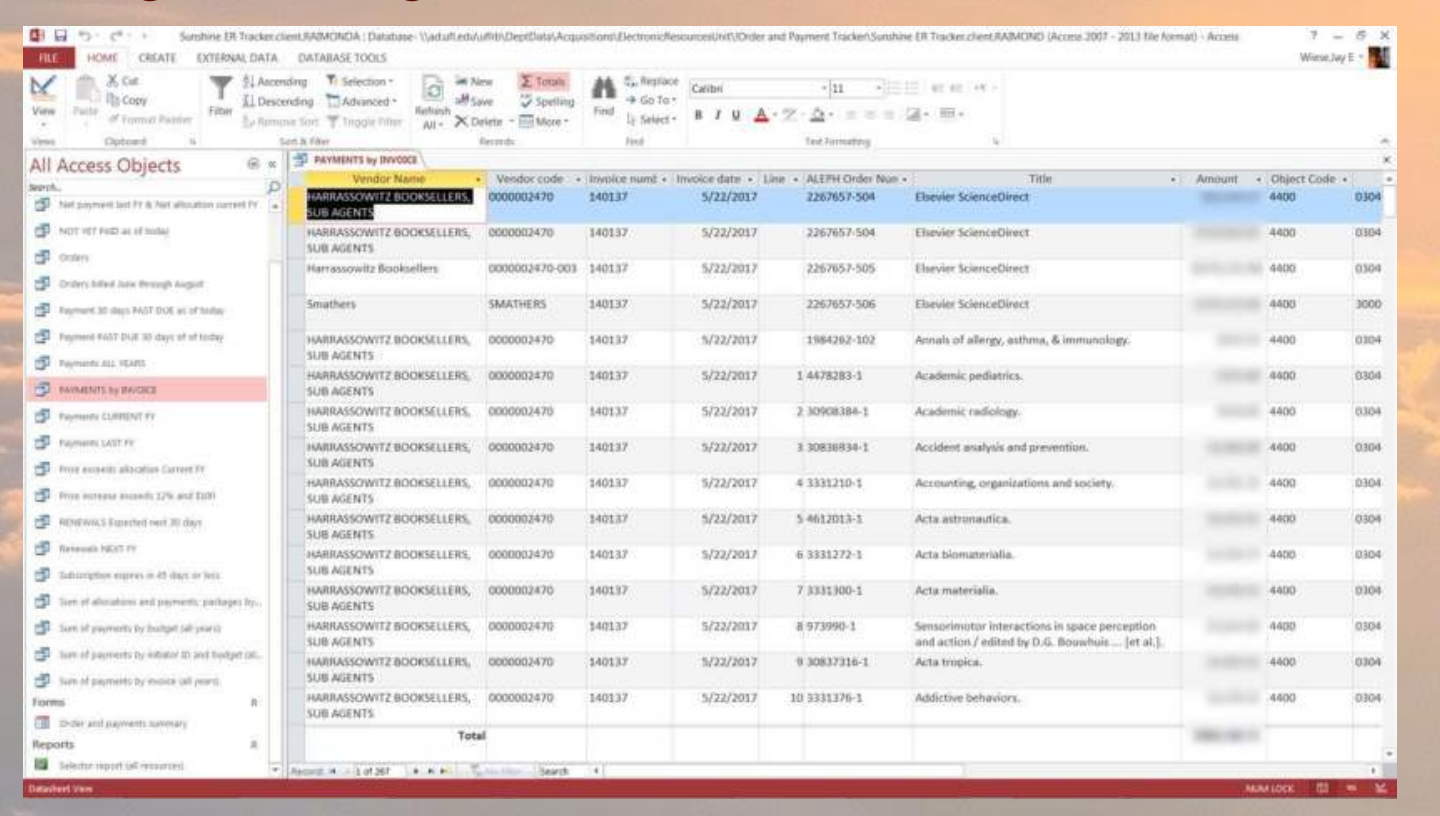

Report--one-click export to Excel

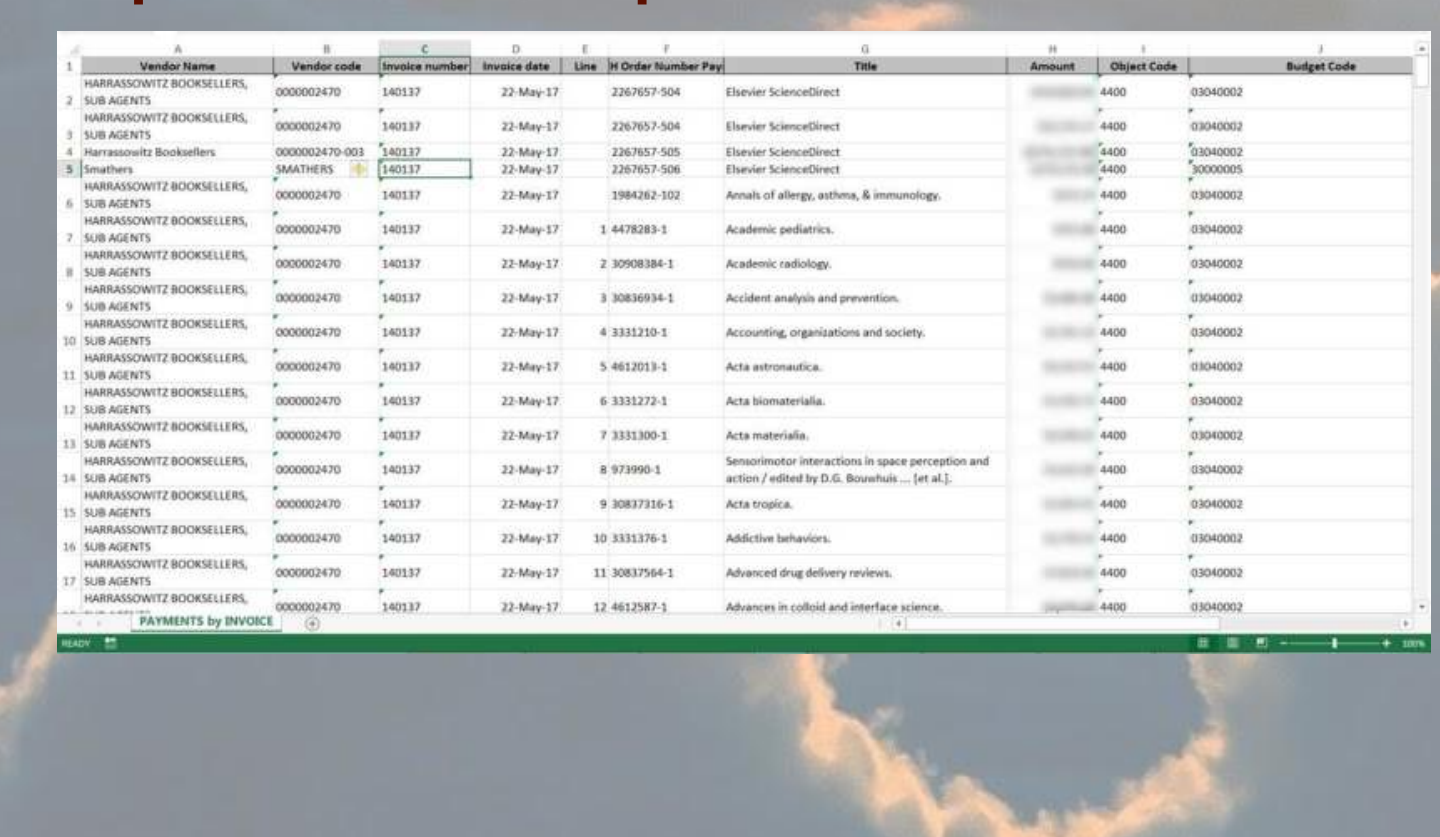

Sunshine ER Tracker: Database structure: Backend-client

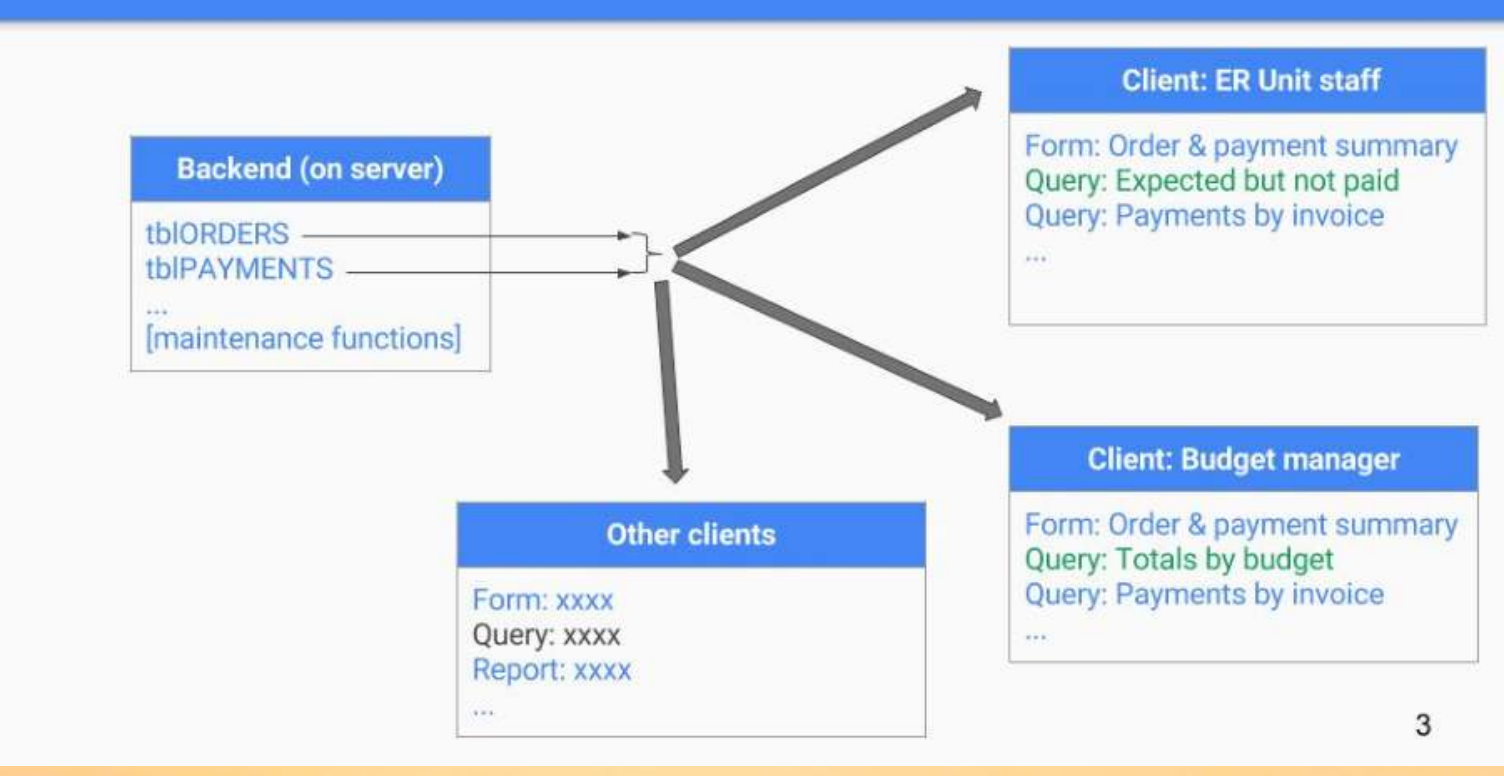

Sunshine ER Tracker: Client data structure

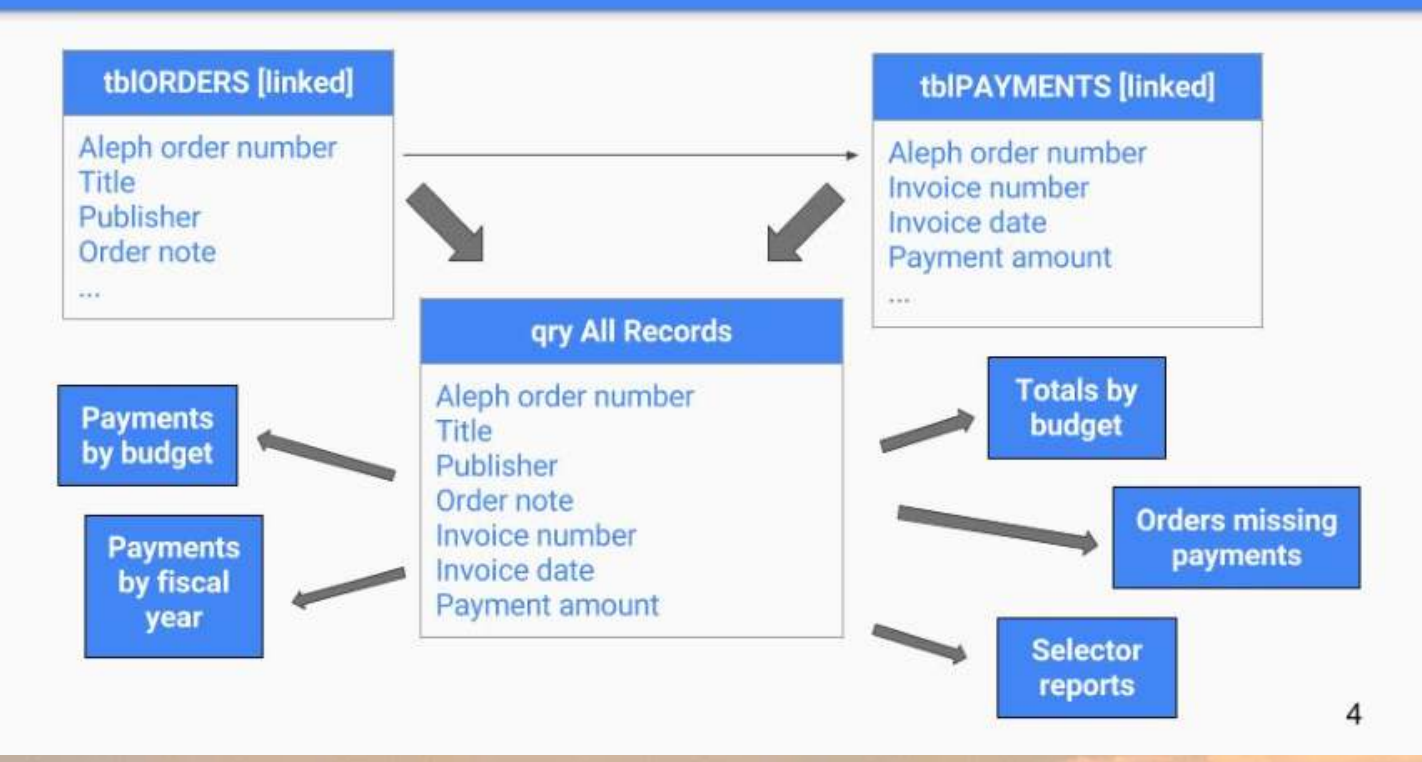

Future directions

- Build a friendlier user interface

- Automate or insource routine maintenance

- Track print and print-plus-online subscriptions

- Add vendor contacts \& admin logins

- Add usage data to calculate cost-per-use

- Can we do what we need with next-gen ILS? 